\title{
ChemComm
}

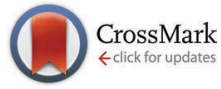

Cite this: Chem. Commun., 2015, 51,7474

Received 31st January 2015,

Accepted 24th March 2015

DOI: $10.1039 / c 5 c c 00922 g$

www.rsc.org/chemcomm

\section{An ultrasensitive impedimetric glycan biosensor with controlled glycan density for detection of lectins and influenza hemagglutinins $\dagger$}

\author{
A. Hushegyi, T. Bertok, P. Damborsky, J. Katrlik and J. Tkac*
}

\begin{abstract}
An impedimetric glycan biosensor with optimised glycan density was applied for the detection of lectins and influenza hemagglutinins down to attomolar concentrations (aM).
\end{abstract}

Glycans, complex carbohydrates attached to proteins, lipids or present on the cell surfaces, play an important role in many cellular processes including immune response, tumour metastasis, infection by bacteria/viruses, inflammation, molecular recognition and cell signaling. ${ }^{1}$ The importance of involvement of glycans in the cellular processes is recognized and understood at an amazing pace and such knowledge has a great potential for developing novel therapeutic and diagnostic tools for numerous diseases. ${ }^{2}$ Glycan biochips based on a fluorescent reading technology developed for highly parallel DNA and protein analysis $^{3}$ became a "must have" tool for multiplexed analysis of binding of glycans with proteins or intact cells/viruses. ${ }^{4}$

Glycan biochips relying on a fluorescent signal reading have some limitations including a need to fluorescently label either glycan or a glycan-binding molecule with a risk that such modification can alter a biorecognition process between a glycan binding protein and surface confined glycan molecules. ${ }^{5}$ Moreover, bleaching of a fluorophore can lead to false negative results or can alter quantitative output from such assays. Traditionally glycans are not printed on the microarray slide with controlled density, which can influence the robustness and reliability of the results obtained by application of fluorescent glycan biochips. Additionally, the detection limit of fluorescent glycan biochips is not particularly impressive and thus, low abundant analyte molecules cannot be detected. ${ }^{6}$ Thus, various alternative and novel assay platforms working in a label-free mode of

Department of Glycobiotechnology, Institute of Chemistry,

Slovak Academy of Sciences, Dubravska cesta 9, 84538 Bratislava, Slovakia.

E-mail: Jan.Tkac@savba.sk; Tel: +421 259410263

$\dagger$ Electronic supplementary information (ESI) available: A full description of experimental conditions, a detailed topological profile of the glycan patterned surface (Fig. S1), the SPR sensorgram (Fig. S2), structures of 2,3-sialyllactose glycan (Fig. S3), Maackia amurensis agglutinin docked with 2,3-sialyllactose (Fig. S4) and H1N1 hemagglutinin docked with 2,3-sialyllactose (Fig. S5). See DOI: $10.1039 / \mathrm{c} 5 \mathrm{cc} 00922 \mathrm{~g}$ operation including electrochemical impedance spectroscopy (EIS) and other electrochemical techniques; field-effect transistor (FET)-based sensing; quartz crystal microbalance; surface plasmon resonance; microcantilever arrays; nanopore sensing; quenching of intrinsic fluorescence of single walled carbon nanotubes; etc. integrated with immobilised glycans and lectins (glycan recognising proteins) have been intensively sought to overcome such limitations as reviewed recently. ${ }^{7}$ It was recently summarised that the nanoscale controlled immobilisation process for glycans and lectins is required to achieve high selectivity and sensitivity assays by these newly developed devices. ${ }^{6,8}$ Moreover, from a diverse range of detection techniques applied so far, especially electrochemical based ones including EIS belong to the most sensitive ones. ${ }^{9}$ For example glycan biosensors with electrochemical detection (cyclic voltammetry and differential pulse voltammetry) exhibit a detection limit down to $0.5 \mathrm{nM},{ }^{10}$ FETbased glycan biosensors offer low $\mathrm{nM}$ level, ${ }^{11} 1 \mathrm{fM}^{12}$ or $\mathrm{aM}^{13}$ detection limits depending on construction formats and EISbased glycan biosensors were able to detect glycan binding proteins down to $0.12 \mathrm{nM} .{ }^{14}$ For comparison glycan biosensors based on surface plasmon resonance or localised surface plasmon resonance can detect analytes down to $0.2 \mathrm{nM}^{15}$ and cantilever array based glycan devices can detect analytes down to 91 pM. $^{16}$

Impedimetric antibody and lectin based biosensors can detect proteins and glycoproteins down to aM level, ${ }^{9 b}$ but so far impedimetric glycan biosensors could not detect such low levels of analytes. ${ }^{14}$ In our previous work we focused on the development of ultrasensitive impedimetric lectin biosensors with controlled architecture at the nanoscale in glycoprofiling (glycoprotein analysis) of some diseases. ${ }^{17}$ In this work we wanted to apply protocols previously developed for immobilisation of lectins for the development of ultrasensitive glycan biosensors. We show for the first time that aM detection limits by impedimetric glycan biosensors are achievable. This ultrasensitive analysis was possible by application of an optimised immobilisation process with controlled density of glycans achieved by formation of a mixed self-assembled monolayer to tune the density of functional carboxylic groups for 
analysis of three different analytes i.e. Maackia amurensis agglutinin (MAA) and two hemagglutinins H1N1 and H5N1.

Polycrystalline gold electrodes were extensively cleaned to remove organic contaminants and gold oxide layer deposited during electrochemical cleaning as described previously ${ }^{18}$ with details provided in the ESI. $\dagger$ Gold electrodes were patterned by a mixed self-assembled monolayer (SAM), prepared from a mixture of two thiols, which is an effective way to control the density of functional ligands on surfaces (initially developed for immobilisation of lectins). ${ }^{17 b}$ A functional thiol (11-mercaptoundecanoic acid, MUA) was diluted by 6-mercaptohexanol ( $\mathrm{MH})$ by changing the amount of MUA in a mixture from $5 \%$ to $50 \%$. In the next step a - $\mathrm{COOH}$ group of MUA was activated by the EDC-NHC mixture to form an active ester. ${ }^{17 b}$ Then, amine-terminated glycan (Fig. 1a and b) was added for covalent immobilisation of a glycan. Finally, the glycan biosensor was incubated with MAA (Fig. 1c) to find out which glycan density is optimal for binding of MAA. Faradaic EIS investigation described in the ESI, $\dagger$ showed that charge transfer resistance $R_{\mathrm{ct}}$, read as a diameter of a semicircle from a Nyquist plot (Fig. 2a), of the SAM was $42.1 \mathrm{k} \Omega$ and this value decreased to

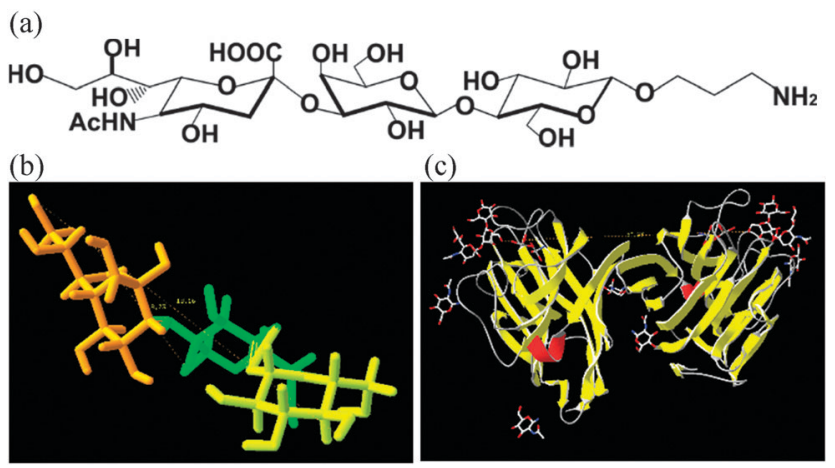

Fig. 1 (a) Chemical structure of the amine glycan derivative of 2,3sialyllactose with a formula Neu5Ac $\alpha 2-3 \mathrm{Gal} \beta 1-4 \mathrm{Glc} \beta-\mathrm{O}-\left(\mathrm{CH}_{2}\right)_{3}-\mathrm{NH}_{2}$ applied for construction of a glycan biosensor, (b) a 3-D structure of 2,3-sialyllactose and (c) a structure of Maackia amurensis agglutinin (lectin) docked with 2,3-sialyllactose (pdb code: 1DBN). (a)

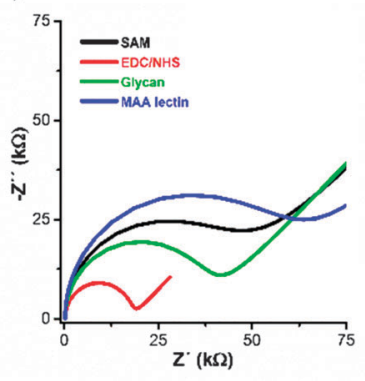

(b)

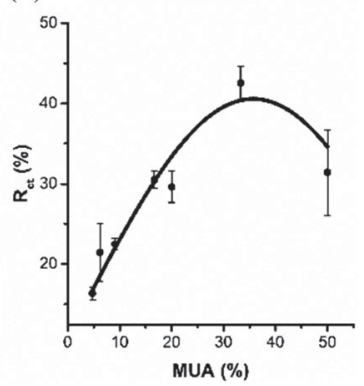

Fig. 2 (a) Impedimetric characterisation of the build-up process for preparation of the glycan biosensor with the formation of a mixed SAM composed of 11-meracptoundecanoic acid (MUA) and 6-mercaptohexanol (SAM), after activation by a coupling reagent (EDC/NHS), after covalent immobilisation of 2,3-sialyllactose (glycan) and after interaction with Maackia amurensis agglutinin (MAA lectin) and (b) optimisation of the MUA ratio within a mixed SAM for preparation of a glycan biosensor evaluated by MAA lectin interaction. (a)

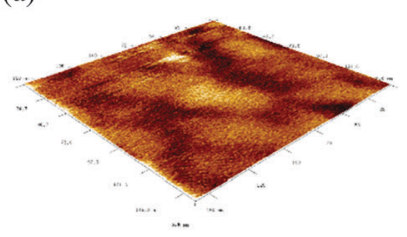

(c)

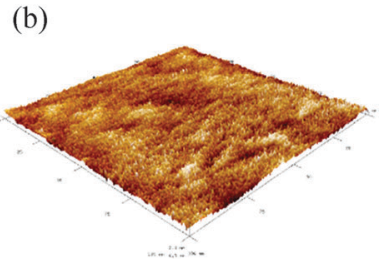

(d)
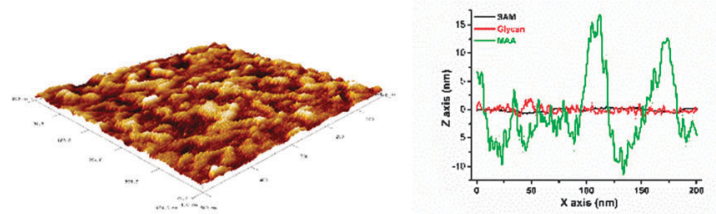

Fig. 3 Atomic force microscopy (AFM) images of (a) mixed SAM composed of 11-meracptoundecanoic acid and 6-mercaptohexanol, (b) 2,3-sialyllactose covalently immobilised on SAM, (c) incubation of Maackia amurensis agglutinin (MAA) with a glycan surface and (d) AFM profile showing surface roughness for a mixed SAM (SAM), a glycan bound surface (glycan) and after incubation of the glycan interface with MAA lectin (MAA).

$17.6 \mathrm{k} \Omega$, after EDC/NHS treatment due to an effective decrease of the negative charge on the SAM. The glycan immobilisation $R_{\mathrm{ct}}$ increased to $36.4 \mathrm{k} \Omega$, and further to the value of $55.5 \mathrm{k} \Omega$ after incubation of the glycan biosensor with MAA (770 pM) (Fig. 2a). The optimisation study aimed to find the optimal composition of a mixed SAM revealed that the glycan biosensor can detect $770 \mathrm{pM}$ MAA with the highest response, when SAM was prepared from a thiol mixture containing 33.3\% of MUA (Fig. 2b).

Atomic force microscopy (AFM) analysis of the glycan modified surface showed the presence of individual features not seen on a SAM modified gold surface (Fig. 3) separated by an average distance of $(2.7 \pm 0.3) \mathrm{nm}$ (Fig. S1, ESI $\dagger$ ), which are attributed to individual glycan chains. The glycan patterned surface exhibited a mean square roughness $R_{\mathrm{q}}=0.65 \mathrm{~nm}$, the value of which is significantly larger compared to the plain mixed SAM with an $R_{\mathrm{q}}=0.39 \mathrm{~nm}$ (Fig. 3). When the glycan surface was finally incubated with MAA $R_{\mathrm{q}}$ increased to the value of $6.45 \mathrm{~nm}$, confirming the ability of a glycan bioreceptive layer to bind its analyte MAA (Fig. 3d). A difference in the topology between a glycan bound layer and plain SAM is clearer compared to a recently published study ${ }^{19}$ and allowed us to calculate glycan density as $(22.7 \pm 2.7) \mathrm{pmol} \mathrm{cm}^{-2}((1.4 \pm 0.2) \times$ $10^{13}$ glycan molecules per $\mathrm{cm}^{2}$ ).

When an independent method i.e. SPR was applied to calculate glycan density, the SPR response of $440 \mu \mathrm{RIU}$ (Fig. S2, ESI $\dagger$ ) corresponds to a glycan density of $61.8 \mathrm{pmol} \mathrm{cm}^{-2}\left(3.7 \times 10^{13}\right.$ glycan molecules per $\mathrm{cm}^{2}$ ). There are two facts worth mentioning regarding SPR assays: (1) a correlation factor of $1000 \mu \mathrm{RIU}=1 \mathrm{ng}$ $\mathrm{mm}^{-2}$ provided by the manufacturer for proteins can be different for glycan molecules; and (2) a higher driving force for delivery of EDC/NHS or the glycan molecule was applied during the SPR experimental run under flow conditions compared to static immobilisation of glycan on an AFM gold chip. Nevertheless, both values of glycan density obtained here fall well within the range of $7.2 \times$ $10^{12} \mathrm{~cm}^{-2}-5.2 \times 10^{13} \mathrm{~cm}^{-2}$ obtained in a previous study for diluted mannosyl moieties. ${ }^{19}$ Taking into account the diameter of 2,3sialyllactose (Fig. S3, ESI $\dagger$ ), the theoretical full glycan monolayer 
should have a density of $1.4 \times 10^{14} \mathrm{~cm}^{-2}$, in agreement with the experimental value of $1.2 \times 10^{14} \mathrm{~cm}^{-2}$ obtained for mannose, ${ }^{19}$ suggesting that optimal glycan density for lectin binding on the surface in this study is close to $10 \%$ of theoretical coverage. Since the distance between the binding sites in MAA is approx. $5.0 \mathrm{~nm}$ (Fig. S4, ESI $\dagger$ ), the highest MAA binding at optimal glycan density (glycan separation of $2.7 \mathrm{~nm}$ ) does not allow bivalent interaction. This is in agreement with a previous study, which concluded that the highest lectin binding was achieved on glycan surfaces allowing monovalent interactions. ${ }^{19}$ From the structure of hemagglutinin H1N1 (a protein from influenza viruses) (Fig. S5, ESI $\dagger$ ) a protein diameter with a binding site bound to the glycan modified surface of $\sim 3.5 \mathrm{~nm}$ could be read, a value smaller than for MAA ( $\sim 5.3 \mathrm{~nm}$, Fig. S4, ESI $\dagger$ ) and thus binding of HA to the glycan modified surface should be less constrained compared to monovalent MAA binding.

The glycan biosensor developed was then calibrated with two different glycan binding proteins - lectins (MAA and Datura stramonium lectin - DSL) and hemagglutinins H1N1 and H5N1. Results indicated that the glycan biosensor containing sialyllactose with $\alpha$-2,3-bound sialic acid specifically interact with MAA, which is preferentially binding glycans with terminal $\alpha$-2,3-bound sialic acid. The glycan biosensor could detect this lectin in the concentration window of $8 \mathrm{aM}-80 \mathrm{nM}$ (i.e. 10 orders of magnitude) (Fig. 4a). DSL binding to $\beta$-1,4-linked $N$-acetylglucosamine oligomers, being a negative control, did not exhibit any significant binding until $8 \mathrm{pM}$ and only then the response toward 2,3-sialyllactose modified interface increased (Fig. 4a). Serum albumins are quite often applied as probes to investigate non-specific interactions with bioreceptive layers, ${ }^{20}$ this is why an additional control experiment was performed by the investigation of binding of human serum albumin (HSA) to the glycan modified surface (HSA with an isoelectric point $\mathrm{pI}=4.4^{21}$ comparable to $\mathrm{pI}=4.7$ for $\mathrm{MAA}$ lectin ${ }^{22}$ ) without any significant binding in a concentration window of $140 \mathrm{aM}-14 \mathrm{nM}$ (Fig. 4a), suggesting a specific biorecognition of surface confined 2,3-sialyllactose by MAA. H5N1 could be detected in a concentration window of $140 \mathrm{aM}-14 \mathrm{nM}$ (i.e. 9 orders of magnitude, if a background value of $\Delta R_{\mathrm{ct}}(\%)$ at a concentration of $1.4 \mathrm{fM}$ is not taken into account), while the response towards H1N1

(a)

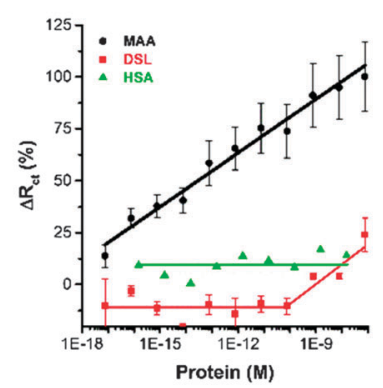

(b)

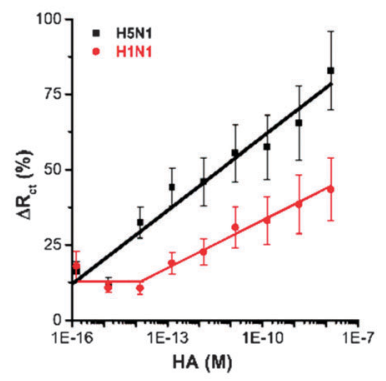

Fig. 4 Calibration of the glycan biosensor by (a) two different lectins Maackia amurensis agglutinin (MAA), Datura stramonium lectin (DSL) and human serum albumin (HSA); and (b) two different influenza hemagglutinins H5N1 (black) and H1N1 (red). was negligible up to $14 \mathrm{fM}$ and only then linearly increased up to a concentration of $14 \mathrm{nM}$ (6 orders of magnitude) (Fig. 4b). The lowest detection limit for determination of lectin with an EIS-based glycan biosensor so far is $0.12 \mathrm{nM} .{ }^{14 c}$ A field-effect transistor (FET)based device relying on silicon nanowires could detect lectins down to $2 \mathrm{nM}^{11 b}$ or $1 \mathrm{fM}^{12}$ Other techniques exhibit detection limits for lectins comparable to glycan biochips. ${ }^{6}$ So far hemagglutinins have not been determined using EIS-based glycan biosensors, but FETbased analysis was successfully applied. In this particular case $\mathrm{H} 1 \mathrm{~N} 1$ and H5N1 could be detected in a concentration window of $50 \mathrm{aM}-5 \mathrm{nM}$ and $500 \mathrm{zM}-500 \mathrm{pM}$, respectively. ${ }^{13}$

It is quite interesting that an interface modified by $\alpha$-2,3-linked sialic acid in sialyllactose bind in our study besides H5N1 also H1N1, which should recognise $\alpha$-2,6-linked sialic acid in sialyllactose. ${ }^{23}$ Hemagglutinins from avian influenza viruses (i.e. H5N1) preferentially bind to $\alpha$-2,3-linked sialic acid terminated glycans, while hemagglutinins from human influenza viruses (i.e. H1N1) preferentially bind to $\alpha-2,6$-linked sialic acid terminated glycans, but such interactions are more complex than previously thought. ${ }^{24}$ Other attributes such as glycan topology (i.e. cone-like vs. umbrellalike structure), the effect of neighbouring glycan and proper spacing of minimal glycan epitopes can play significant roles in the viral recognition of host cellular glycans via hemagglutinins. ${ }^{23 b, 25}$ Interrogation of glycan biochips with hemagglutinins isolated from different influenza viruses revealed that some human H1N1 hemagglutinins can bind to $\alpha$-2,3-linked sialic acid terminated glycans and avian H5N1 hemagglutinins can bind to $\alpha-2,6$-linked sialic acid terminated glycans. ${ }^{26}$ Another recent study showed that H1N1 hemagglutinin isolated from the viral strain New Caledonia 20/99 (used in this study) not only binds effectively to various glycans with $\alpha$-2,3-linked sialic acid termination, but more interestingly enhancement of binding was observed, when galactose next to terminal sialic acid was modified by a negatively charged sulfo group. ${ }^{27}$ The most recent study showed that the binding preference of intact H1N1 influenza viruses (A/Puerto Rico/8/34) to 2,3-sialyllactose or 2,6-sialyllactose modified glycan microarrays exhibits binding specificity depending on glycan density i.e. at low printed glycan density (from $0.1 \mathrm{mM}$ glycan solution) the H1N1 influenza virus exhibits preferential binding to 2,6sialyllactose, while at higher printed glycan density (1-10 mM of glycan in solution), the same virus preferentially binds to 2,3-sialyllactose. ${ }^{28}$ This study is in agreement with the conclusion of another study that alternative moieties including sulfonated ones may be important in the recognition of host glycan receptors by influenza viruses. ${ }^{29}$ Thus, a more systematic investigation of glycan density, topology and the presence of various charged species within glycan interfaces on binding of viral agglutinins is needed for the determination of various different viral strains. Impedimetric glycan biosensors based on gold surfaces patterned by thiols terminated in numerous functionalities in a flexible way can shed light on interaction between glycan epitopes and viral proteins. ${ }^{14 b}$ Moreover, impedimetric glycan biosensors could be useful for analysis of activities of glycan processing enzymes, not yet performed. ${ }^{30}$

We have developed the most sensitive impedimetric glycan biosensor for analysis of lectins with the detection limit 7 orders 
of magnitude lower compared to the best described glycan biosensor. The glycan biosensor described here is the first impedimetric glycan biosensor for analysis of hemagglutinins with detection limits down to the attomolar level with sensitivity similar to the best glycan biosensor based on FET described so far. ${ }^{13}$ Moreover, this study provides ultrasharp visualisation of glycans immobilised on surfaces by AFM.

Funding from the Slovak research and development agency APVV 0282-11 and VEGA 2/0162/14 is acknowledged. The research leading to these results has received funding from the European Research Council under the European Union's Seventh Framework Program (FP/2007-2013)/ERC Grant Agreement no. 311532 .

\section{Notes and references}

1 (a) N. C. Reichardt, M. Martín-Lomas and S. Penadés, Chem. Soc. Rev., 2013, 42, 4358; (b) S. Park, J. C. Gildersleeve, O. Blixt and I. Shin, Chem. Soc. Rev., 2013, 42, 4310; (c) A. Varki, Essentials of Glycobiology, Cold Spring Harbor Laboratory Press, Cold Spring Harbor, N.Y., 2009; (d) S. Cecioni, A. Imberty and S. Vidal, Chem. Rev., 2015, 115, 525.

2 (a) W. R. Alley, B. F. Mann and M. V. Novotny, Chem. Rev., 2013, 113, 2668; (b) D. R. Burton, P. Poignard, R. L. Stanfield and I. A. Wilson, Science, 2012, 337, 183; (c) M. Dalziel, M. Crispin, C. N. Scanlan, N. Zitzmann and R. A. Dwek, Science, 2014, 343, 37, DOI: 10.1126/ science.1235681; (d) A. Rouvinski, P. Guardado-Calvo, G. Barba-Spaeth, S. Duquerroy, M.-C. Vaney, C. M. Kikuti, M. E. N. Sanchez, W. Dejnirattisai, W. Wongwiwat, A. Haouz, C. Girard-Blanc, S. Petres, W. E. Shepard, P. Despres, F. Arenzana-Seisdedos, P. Dussart, J. Mongkolsapaya, G. R. Screaton and F. A. Rey, Nature, 2015, DOI: 10.1038/nature14130; (e) M. S. Macauley, B. M. Arlian, C. D. Rillahan, P.-C. Pang, N. Bortell, M. C. G. Marcondes, S. M. Haslam, A. Dell and J. C. Paulson, J. Biol. Chem., 2014, 289, 35149; $(f)$ S. Bournazos, F. Klein, J. Pietzsch, M. S. Seaman, M. C. Nussenzweig and J. V. Ravetch, Cell, 2014, 158, 1243; $(g)$ R. A. Medina and A. GarcíaSastre, Nat. Rev. Microbiol., 2011, 9, 590.

3 (a) K. Drickamer and M. E. Taylor, Genome Biol., 2002, 3, 1034; (b) S. Fukui, T. Feizi, C. Galustian, A. M. Lawson and W. Chai, Nat. Biotechnol., 2002, 20, 1011; (c) B. T. Houseman and M. Mrksich, Chem. Biol., 2002, 9, 443; (d) S. Park and I. Shin, Angew. Chem., Int. $E d .$, 2002, 41, 3180; (e) D. Wang, S. Liu, B. J. Trummer, C. Deng and A. Wang, Nat. Biotechnol., 2002, 20, 275.

4 (a) C. M. Arthur, R. D. Cummings and S. R. Stowell, Curr. Opin. Chem. Biol., 2014, 18, 55; (b) O. Blixt and U. Westerlind, Curr. Opin. Chem. Biol., 2014, 18, 62; (c) R. D. Cummings and J. M. Pierce, Chem. Biol., 2014, 21, 1; (d) A. Geissner, C. Anish and P. H. Seeberger, Curr. Opin. Chem. Biol., 2014, 18, 38; (e) S. A. Svarovsky and L. Joshi, Anal. Methods, 2014, 6, 3918; $(f)$ J. E. Stencel-Baerenwald, K. Reiss, D. M. Reiter, T. Stehle and T. S. Dermody, Nat. Rev. Microbiol., 2014, 12, 739; $(g)$ N. Laurent, J. Voglmeir and S. L. Flitsch, Chem. Commun., 2008, 4400.

5 (a) P. Gemeiner, D. Mislovičová, J. Tkáč, J. Švitel, V. Pätoprstý, E. Hrabárová, G. Kogan and T. Kožár, Biotechnol. Adv., 2009, 27, 1; (b) J. Katrlík, J. Švitel, P. Gemeiner, T. Kožár and J. Tkac, Med. Res. Rev., 2010, 30, 394.

6 A. Hushegyi and J. Tkac, Anal. Methods, 2014, 6, 6610.

7 (a) T. Bertók, J. Katrlík, P. Gemeiner and J. Tkac, Microchim. Acta, 2013, 180, 1; (b) J. Q. Gerlach, S. Cunningham, M. Kane and L. Joshi, Biochem. Soc. Trans., 2010, 38, 1333; (c) B. Mu, J. Zhang, T. P. McNicholas, N. F. Reuel, S. Kruss and M. S. Strano, Acc. Chem. Res., 2014, 47, 979; (d) N. F. Reuel, B. Grassbaugh, S. Kruss, J. Z. Mundy, C. Opel, A. O. Ogunniyi, K. Egodage, R. Wahl, B. Helk, J. Zhang, Z. I. Kalcioglu, K. Tvrdy, D. O. Bellisario, B. Mu, S. S. Blake, K. J. Van Vliet, J. C. Love, K. D. Wittrup and M. S. Strano, ACS Nano, 2013, 7, 7472; (e) N. F. Reuel, B. Mu, J. Zhang, A. Hinckley and M. S. Strano, Chem. Soc. Rev., 2012, 41, 5744; $(f)$ J. Tkac, T. Bertok, J. Nahalka and P. Gemeiner, Methods Mol. Biol., 2014, 1200, 421.

8 L'. Kluková, T. Bertók, P. Kasák and J. Tkac, Anal. Methods, 2014, 6, 4922 .
9 (a) E. Palecek and M. Bartosik, Chem. Rev., 2012, 112, 3427; (b) E. Paleček, J. Tkáč, M. Bartošík, T. Bertók, V. Ostatná and J. Paleček, Chem. Rev., 2015, 115, 2045.

10 (a) X.-P. He, X.-W. Wang, X.-P. Jin, H. Zhou, X.-X. Shi, G.-R. Chen and Y.-T. Long, J. Am. Chem. Soc., 2011, 133, 3649; (b) H. Zeng, J. Yu, Y. Jiang and X. Zeng, Biosens. Bioelectron., 2014, 55, 157.

11 (a) Y. Chen, H. Vedala, G. P. Kotchey, A. Audfray, S. Cecioni, A. Imberty, S. Vidal and A. Star, ACS Nano, 2012, 6, 760; (b) H. Vedala, Y. Chen, S. Cecioni, A. Imberty, S. b. Vidal and A. Star, Nano Lett., 2010, 11, 170; (c) M. Ali, S. Nasir, P. Ramirez, J. Cervera, S. Mafe and W. Ensinger, J. Phys. Chem. C, 2013, 117, 18234.

12 G.-J. Zhang, M. J. Huang, J. A. J. Ang, Q. Yao and Y. Ning, Anal. Chem., 2013, 85, 4392.

13 S. Hideshima, H. Hinou, D. Ebihara, R. Sato, S. Kuroiwa, T. Nakanishi, S.-I. Nishimura and T. Osaka, Anal. Chem., 2013, 85, 5641.

14 (a) S. Szunerits, J. Niedziǒłka-Jönsson, R. Boukherroub, P. Woisel, J.-S. b. Baumann and A. Siriwardena, Anal. Chem., 2010, 82, 8203; (b) O. A. Loaiza, P. J. Lamas-Ardisana, E. Jubete, E. Ochoteco, I. Loinaz, G. n. Cabañero, I. García and S. Penadés, Anal. Chem., 2011, 83, 2987; (c) Z. Wang, C. Sun, G. Vegesna, H. Liu, Y. Liu, J. Li and X. Zeng, Biosens. Bioelectron., 2013, 46, 183.

15 (a) N. Maalouli, A. Barras, A. Siriwardena, M. Bouazaoui, R. Boukherroub and S. Szunerits, Analyst, 2013, 138, 805; (b) G. Bellapadrona, A. B. Tesler, D. Grunstein, L. H. Hossain, R. Kikkeri, P. H. Seeberger, A. Vaskevich and I. Rubinstein, Anal. Chem., 2012, 84, 232; (c) T. Nagatsuka, H. Uzawa, K. Sato, S. Kondo, M. Izumi, K. Yokoyama, I. Ohsawa, Y. Seto, P. Neri, H. Mori, Y. Nishida, M. Saito and E. Tamiya, ACS Appl. Mater. Interfaces, $2013,5,4173$.

16 (a) K. Gruber, T. Horlacher, R. Castelli, A. Mader, P. H. Seeberger and B. A. Hermann, ACS Nano, 2011, 5, 3670; (b) K. Gruber, B. Hermann and P. Seeberger, Angew. Chem., Int. Ed., 2011, 50, A46.

17 (a) T. Bertok, P. Gemeiner, M. Mikula, P. Gemeiner and J. Tkac, Microchim. Acta, 2013, 180, 151; (b) T. Bertok, L. Klukova, A. Sediva, P. Kasák, V. Semak, M. Micusik, M. Omastova, L. Chovanová, M. Vlček, R. Imrich, A. Vikartovska and J. Tkac, Anal. Chem., 2013, 85, 7324; $(c)$ T. Bertok, A. Sediva, J. Katrlik, P. Gemeiner, M. Mikula, M. Nosko and J. Tkac, Talanta, 2013, 108, 11; (d) T. Bertok, A. Sediva, A. Vikartovska and J. Tkac, Int. J. Electrochem. Sci., 2014, 9, 890; (e) L. Klukova, T. Bertok, M. Petrikova, A. Sediva, D. Mislovicova, J. Katrlik, A. Vikartovska, J. Filip, P. Kasak, A. Andicsová-Eckstein, J. Mosnáček, J. Lukáč, J. Rovenský, R. Imrich and J. Tkac, Anal. Chim. Acta, 2015, 853, 555.

18 J. Tkac and J. J. Davis, J. Electroanal. Chem., 2008, 621, 117.

19 J. Yang, J.-N. Chazalviel, A. Siriwardena, R. Boukherroub, F. Ozanam, S. Szunerits and A. C. Gouget-Laemmel, Anal. Chem., 2014, 86, 10340.

20 J. J. Davis, J. Tkac, R. Humphreys, A. T. Buxton, T. A. Lee and P. Ko Ferrigno, Anal. Chem., 2009, 81, 3314.

21 R. Liu, R. Pidikiti, C.-E. Ha, C. E. Petersen, N. V. Bhagavan and R. G. Eckenhoff, J. Biol. Chem., 2002, 277, 36373.

22 https://www.vectorlabs.com/data/brochures/K4-K7.pdf downloaded on 09.03.2015.

23 (a) C. M. Nycholat, R. McBride, D. C. Ekiert, R. Xu, J. Rangarajan, W. Peng, N. Razi, M. Gilbert, W. Wakarchuk, I. A. Wilson and J. C. Paulson, Angew. Chem., Int. Ed., 2012, 51, 4860; (b) Y. Watanabe, M. S. Ibrahim, Y. Suzuki and K. Ikuta, Trends Microbiol., 2012, 20, 11.

24 H. Shelton, G. Ayora-Talavera, J. Ren, S. Loureiro, R. J. Pickles, W. S. Barclay and I. M. Jones, J. Virol., 2011, 85, 1875.

25 (a) C. A. Bewley, Nat. Biotechnol., 2008, 26, 60; (b) Z. Wang, Z. S. Chinoy, S. G. Ambre, W. Peng, R. McBride, R. P. de Vries, J. Glushka, J. C. Paulson and G.-J. Boons, Science, 2013, 341, 379.

26 A. Chandrasekaran, A. Srinivasan, R. Raman, K. Viswanathan, S. Raguram, T. M. Tumpey, V. Sasisekharan and R. Sasisekharan, Nat. Biotechnol., 2008, 26, 107.

27 K. C. Bradley, C. A. Jones, S. M. Tompkins, R. A. Tripp, R. J. Russell, M. R. Gramer, J. Heimburg-Molinaro, D. F. Smith, R. D. Cummings and D. A. Steinhauer, Virology, 2011, 413, 169.

28 M. L. Huang, M. Cohen, C. J. Fisher, R. T. Schooley, P. Gagneux and K. Godula, Chem. Commun., 2015, 51, 5326.

29 L. Glaser, G. Conenello, J. Paulson and P. Palese, Virus Res., 2007, 126, 9. 30 (a) C. J. Gray, M. J. Weissenborn, C. E. Eyers and S. L. Flitsch, Chem. Soc. Rev., 2013, 42, 6378; (b) P. J. Halling, R. V. Ulijn and S. L. Flitsch, Curr. Opin. Biotechnol., 2005, 16, 385; (c) N. Laurent, R. Haddoub and S. L. Flitsch, Trends Biotechnol., 2008, 26, 328. 